\title{
Pemanfaatan Ekstrak Daun Mangrove (Rhizophora mucronata sp.) dengan Variasi Pelarut Sebagai Bahan Aktif Sediaan Farmasi Terapi Anti Kanker
}

\author{
Anita Ratna Faoziyah, Wahyu Kurniawan
}

\begin{abstract}
This research was done to study mangrove leaves (Rhizophora mucronata sp.) utilization in the Cilacap regency brackish waters. The research goal is to make nano emulsion from mangrove plants as an alternative to increase the economic value of mangrove. This research method has 2 phases. In the first phase, mangrove leaves was extracted using various solvent. In the second phase mangrove leaves extract was formulated as nano emulsion as anti-cancer treatment along as an alternative to increase mangrove leaves economic value. Extraction results of mangrove leaves using various solvent such as hexane, ethyl acetate and ethanol show that using ethanol p.a solvent with the young leaves of mangrove giving the highest amount extract as much as $18.24 \%$.
\end{abstract}

Mangrove leaves extract nano emulsion can be prepared using Self-Nano Emulsifying Drug Delivery System (SNEDDS) technique. The SNEDDS technique nano emulsion formulation started with 14 formulas. The best formula from this study was using Tween 80 : PEG 400 : Fish Oil as much as $6 \mathrm{ml}: 1$ $\mathrm{ml}: 1 \mathrm{ml}$ dosage ratio. Using the best formula, it was added with $5 \mathrm{mg}$ of mangrove leaves extract. The result test of Drug Loading, calculation of Emulsification Time and Dissolution test show that mangrove leaves extract has the potential to be used as an active substance anti-cancer on nano emulsion manufacturing.

Keyword: Mangrove leaf extract, solvent variation and nano emulsion

\section{Intisari}

Penelitian ini dilakukan untuk menelaah pemanfaatan daun mangrove (Rhizophora mucronata sp.) di perairan payau kabupaten Cilacap. Tujuan penelitian ini ialah pembuatan nano emulsi dari tanaman mangrove sebagai alternatif peningkatan nilai ekonomis mangrove. Metode penelitian ini dilakukan dalam 2 tahap. Pada tahap pertama dilakukan ekstraksi daun mangrove dengan variasi pelarut. Pada tahap kedua dilakukan formulasi nano emulsi ekstrak daun mangrove sebagai terapi anti kanker dan sebagai alternatif peningkatan nilai ekonomis dari daun mangrove. Hasil ektraksi daun mangrove

Afiliasi Penulis

Prodi D3 Farmasi STIKES Al-Irsyad Al-Islamiyyah Cilacap

Jl. Cerme No. 24 Sidanegara Cilacap

Korespondensi kepada

A.R. Faoziyah

anitahendrayatno@gmail.com dengan variasi pelarut seperti hexane, etil asetat dan etonol memperlihatkan bahwa pengunaan pelarut etanol p.a pada daun mangrove muda diperoleh hasil ekstraksi paling besar sebesar 18,24\%.

Nano emulsi ekstrak daun mangrove dapat dipreparasi dengan teknik Self-Nano Emulsifying Drug Delivery System (SNEDDS). Formulasi nano emulsi dengan teknik 
SNEDDS dilakukan dengan membuat 14 formula. Formula yang paling tepat adalah formulasi dengan perbandingan Tween 80 : PEG 400 : Minyak Ikan dengan perbandingan sediaan sebanyak $6 \mathrm{ml}: 1 \mathrm{ml}$ : $1 \mathrm{ml}$. Hasil formulasi nanoemulsi yang tepat ditambahkan ekstrak daun mangrove dengan dosis yang telah ditentukan sebanyak $5 \mathrm{mg}$. Hasil uji Drug Loading, perhitungan Emulsification Time dan uji Disolusi menunjukan bahwa ekstrak daun mangrove memiliki potensi untuk digunakan sebagai zat aktif pembuatan nano emulsi terapi anti kanker.

Kata kunci: Ekstrak daun mangrove, variasi pelarut dan nano emulsi

\section{Pendahuluan}

Kabupaten Cilacap terkenal dengan letak geografis di pantai selatan dengan salah satu bagian wilayahnya adalah kawasan Segara Anakan yang banyak terdapat tanaman mangrove. Keberadaan tanaman mangrove di kawasan Segara Anakan berfungsi sebagai tempat pemijahan (spawning ground) dan tempat pengasuhan (nursery ground). Akar tanaman mangrove dapat berfungsi sebagai pelindung dari hartaman ombak dan sebagai biogeochemical barriers terhadap berbagai jenis polutan limbah logam berat.

Tanaman mangrove memiliki manfaat di bidang kesehatan di mana sebagian besar bagian dari tanaman ini dapat dimanfaatkan sebagai bahan obat-obatan alami, selain itu beberapa spesies tanaman mangrove juga dapat dimanfaatkan sebagai bahan insektisida dan pestisida alami (Purnobasuki, 2004). Tumbuhan mangrove banyak terdapat di daerah pesisir dan payau. Hasil penelitian dari Feliatra (2000) dan Yasmon (2000) menunjukan bahwa beberapa spesies mangrove dapat berfungsi sebagai antimikroba khususnya terhadap bakteri Vibrio Sp.

Hutan mangrove yang terdapat di Segara Anakan kabupaten Cilacap memiliki luas 24.000 ha dan didominasi oleh 23 spesies mangrove. Salah satu spesies tanaman mangrove yang paling banyak dijumpai adalah spesies mangrove Rhizophora mucronata (Anggora, 2012). Kandungan senyawa kimia dalam tanaman mangrove adalah fenolit, alkaloid, steroid, saponin, flavonoid dan tanin. Pemanfatan tanaman mangrove sebagai obat tradisional dapat digunakan sebagai anti kanker di mana daun tanaman mangrove spesies Rhizopora mucronata secara invitro mampu menghambat pertumbuhan sel kanker dengan LC 50 sebesar $582.00 \mu \mathrm{g} / \mathrm{mL}$ (Warsinah et.al, 2005).
Pemanfaatan daun mangrove sebagai penghambat pertumbuhan sel kanker dilakukan dengan mengambil ekstrak zat aktif yang terdapat dalam daun mangrove. Pemanfaatan daun mangrove sebagai terapi alternatif penghambat sel kanker dapat diformulasikan dalam sediaan farmasi seperti nanoemulsi. Pembuatan sediaan nano emulsi bertujuan untuk meningkatkan tingkat distribusi dan absorsi obat sebingga pengunaan obat dapat lebih optimal. Selain itu pembuatan nano emulsi dapat menjadi alternative dari pemanfaatan tanaman mangrove sehingga akan meningkatkan nilai ekonomis tanaman mangrove di sekitar Kabupaten Cilacap.

\section{Metode}

\section{Bahan}

Daun mangrove tua, muda dan pucuk spesies Rhizophora mucronata, pelarut polar dan non polar (etanol, etil asetat dan $n$-hexane. Semua pelarut yang digunakan berkualitas p.a), surfaktan dan kosurfaktan seperti minyak ikan cucut botol, tween 80, PEG 400, akuades, $\mathrm{MgCl}_{2}, \mathrm{CaCl}_{2}, \mathrm{KCl}, \mathrm{NaCl}$, $\mathrm{NaHCO}_{3}$, dan $\mathrm{HCl}$.

Alat

Rotary evaporator, neraca analitik digital, sentrifus, mikropipet, $\mathrm{pH}$ meter, Microtube, vortex mixer, alat uji disolusi tipe aparatus I, spet injeksi, waterbath, spektrofotometer, stopwatch.

\section{Metode penelitian}

Penelitian dilakukan dengan dua tahap yaitu tahap pengambilan zat aktif atau ekstrak dari daun mangrove dengan variasi pelarut dan tahap pembuatan sediaan nano emulsi dari ekstrak daun mangrove spesies Rhizophora mucronata sp. Ektraksi daun mangrove dengan langkah-langkah penelitian sebagai berikut: 
Ektraksi daun mangrove pucuk, muda dan tua dengan pelarut yang bersifat polar (etanol), semi polar (etil asetat) dan non polar (n-hexana) dengan metode ektraksi maserasi dan pengocokan sampel sebanyak 200 gr sampel daun mangrove kering, dihaluskan dicampur pelarut sebanyak $200 \mathrm{ml}$ dan dilakukan ektraksi selama 4 jam. Setelah ekstraksi selesai sampel disaring dan dievaporasi untuk menghilangkan pelarut.

Tahap kedua adalah pembuatan sediaan nano partikel dengan teknik Self-Nano Emulsifying Drug Delivery System (SNEDDS). Pembuatan nano emulsi dengan metode SNEDDS dilakukan dengan metode sebagai berikut (Makadia, 2013):

1. Optimasi Formula SNEDDS

a. Optimasi formulasi komposisi surfaktan, kosurfaktan dan minyak. Berdasarkan Software Design Expert untuk campuran 3 komponen maka dibuat 14 formula pada berbagai komposisi campuran untuk ketiga komponen yang akan dioptimasi yaitu surfaktan, ko-surfaktan dan minyak ikan cucut botol (tabel 1).

b. Pembuatan emulsi. Sebanyak $1 \mathrm{~mL}$ calon formula SNEDDS ditambah akuades hingga volume akhir $5 \mathrm{ml}$. Homogenisasi campuran dengan bantuan vortex. Hasil pencampuran yang homogen dan memberikan penampilan visual jernih (uji turbiditas) menjadi tanda awal keberhasilan pembuatan nano emulsi.

c. Pengamatan emulsi. Pengamatan emulsi yang telah terbentuk pada tahap sebelumnya dilakukan secara spektrofotometri (uji transmitan) melalui pengukuran serapan pada panjang gelombang $650 \mathrm{~nm}$ dengan blanko akuades untuk mengetahui tingkat kejernihannya. Semakin jernih atau absorbansi semakin mendekati absorbansi akuades. Lalu pilih 1 formula SNEDDS yang paling jernih dan diuji lagi dengan Particle Size Analyzer

\section{Optimasi Drug Loading}

Optimasi drug loading dilakukan berdasarkan metode Shah et al., 2010. Pertama 5 mg ekstrak daun Rhizophora mucronata ditambahkan ke dalam $1 \mathrm{ml}$ formula optimal SNEDDS kemudian dihomogenkan dengan vortex dan dipanasi. Pengamatan kelarutan ekstrak daun Rhizophora mucronata dalam SNEDDS dilakukan secara visual. Konsentrasi tertinggi yang menghasilkan campuran jernih tanpa keberadaan partikel ekstrak daun Rhizophora mucronata bebas merupakan konsentrasi maksimal yang dapat dicapai.

3. Penghitungan Emulsification Time

Penghitungan emulsification time dilakukan terhadap nano emulsi ekstrak daun Rhizophora mucronata dalam media yaitu artificial gastric fluid tanpa pepsin (tabel 2).

Sebanyak $900 \mathrm{~mL}$ media dikondisikan di atas Dissolution tester dengan kecepatan 120 rpm. SNEDDS $1 \mathrm{~mL}$ berisi ekstrak daun mangrove diteteskan ke dalam media secara cepat. Dilakukan pengamatan terhadap waktu yang diperlukan sejak penetesan hingga terbentuk nano emulsi. Terbentuknya nano emulsi ditandai dengan

Tabel 1 | Komposisi bahan dalam penentuan formula optimum.

\begin{tabular}{ccccc} 
Formulasi & $\begin{array}{c}\text { Surfaktan } \\
\text { (Tween 80) }\end{array}$ & $\begin{array}{c}\text { Ko-surfaktan } \\
\text { (PEG 400) }\end{array}$ & $\begin{array}{c}\text { Minyak } \\
\text { Ikan Cucut }\end{array}$ & Ekstrak \\
\hline $\mathbf{1}$ & 2,667 & 2,667 & 2,667 & - \\
$\mathbf{2}$ & 3,500 & 3,500 & 1,000 & - \\
$\mathbf{3}$ & 6,000 & 1,000 & 1,000 & - \\
$\mathbf{4}$ & 4,333 & 1,833 & 1,833 & - \\
$\mathbf{5}$ & 1,833 & 4,333 & 1,833 & - \\
$\mathbf{6}$ & 1,000 & 3,500 & 3,500 & - \\
$\mathbf{7}$ & 6,000 & 1,000 & 1,000 & - \\
\hline $\mathbf{8}$ & 1000 & 6,000 & 1,000 & - \\
$\mathbf{9}$ & 1000 & 1,000 & 6,000 & - \\
$\mathbf{1 0}$ & 1000 & 6,000 & 1,000 & - \\
$\mathbf{1 1}$ & 1000 & 1,000 & 6,000 & - \\
$\mathbf{1 2}$ & 3,500 & 1,000 & 3,500 & - \\
$\mathbf{1 3}$ & 3,500 & 3,500 & 1,000 & - \\
$\mathbf{1 4}$ & 1,833 & 1,833 & 4,333 & - \\
\hline
\end{tabular}

Keterangan: Jumlah ekstrak dalam formula didapatkan dari hasil uji drug loading maksimal 
Tabel 2 | Formula artificial gastric fluid.

\begin{tabular}{rc} 
Komponen & Jumlah \\
\hline $\mathrm{NaCl}$ & $200 \mathrm{mg}$ \\
\hline $\mathrm{HCl} 37 \%$ & $0,7 \mathrm{~mL}$ \\
\hline Akuades & ad $100 \mathrm{~mL}$ \\
${ }^{*}$ Kondisi pH 1-3 & \\
\hline
\end{tabular}

terlarutnya ekstrak daun mangrove secara sempurna di dalam media.

4. Uji Disolusi atau Pengamatan Laju Pelepasan

Obat

Uji pelepasan obat atau disolusi dilakukan dengan tipe aparatus I (konstruksi basket, 50 rpm), menggunakan media aqudest. Uji disolusi dilakukan dengan memasukkan 900,0 mL media ke dalam labu disolusi, kemudian sebagian labu dicelupkan ke dalam penangas air hingga suhu media mencapai $37 \pm 0,5^{\circ} \mathrm{C}$. Sebuah kapsul dimasukkan ke dalam basket.

Basket diturunkan hingga berjarak 2,5 $\pm 0,2 \mathrm{~cm}$ dari dasar labu, kemudian alat dijalankan dengan kecepatan putaran $50 \mathrm{rpm}$ (Depkes RI, 1995). Sampel diambil 5,0 mL dengan spet injeksi yang dilengkapi dengan filter holder. Pada setiap pengambilan sampel, ke dalam media.

Harus ditambahkan media sebanyak $5,0 \mathrm{~mL}$ dengan suhu $37 \pm 0,5^{\circ} \mathrm{C}$. Pengambilan sampel dilakukan pada menit ke-1, 3, 5, 10, 15, 20, 25, 30, $35,40,45$. Lokasi pengambilan sampel adalah pada daerah di tengah, antara permukaan media dengan permukaan atas dayung dan pada jarak tidak kurang dari $1 \mathrm{~cm}$ dari dinding samping labu. Tiap sampel yang diambil dari media disolusi diukur

Tabel 3 | Hasil ekstraksi daun mangrove Rhizophora mucronata sp.

\begin{tabular}{rcc} 
Solven & $\begin{array}{c}\text { Daun } \\
\text { Mangrove }\end{array}$ & $\begin{array}{c}\text { Hasil } \\
\text { Rendemen (\%) }\end{array}$ \\
\hline \multirow{2}{*}{ Etanol p.a. } & Muda & 18,24 \\
& Tua & 14,80 \\
& Pucuk & 15,58 \\
\hline \multirow{2}{*}{ Etil asetat p.a. } & Muda & 6,55 \\
& Tua & 5,94 \\
\hline & Pucuk & 5,17 \\
\hline Hexana p.a. & Muda & 1,92 \\
& Tua & 2,19 \\
& Pucuk & 2,79 \\
\cline { 2 - 3 }
\end{tabular}

serapannya dengan spektofotometer pada panjang gelombang maksimum.

\section{Hasil \& Pembahasan}

Ektraksi daun mangrove spesies Rhizophora mucronata $s p$. dengan variasi pelarut menunjukan bahwa ektraksi mengunakan pelarut etanol pada daun mangrove muda spesies Rhizopora mucronata menghasilkan rendemen yang paling besar (tabel 3). Hal ini sesuai dengan dengan prinsip ekstaksi yaitu like disoved like atau pengambilan zat aktif dengan palarut akan susuai dengan sifat dari kandungan senyawa dalam sampel. Apabila kandungan senyawa bersifat polar maka pelarut yang polar akan cenderung menarik kuat ke senyawa-senyawa polar dan sebaliknya apabila zat aktif atau kandungan senyawa dalam sampel banyak yang bersifat non polar maka pelarut non polar seperti hexane, benzene akan lebih banyak mendapatkan rendemen dalam proses ektraksinya. Hasil penelitian dari Anggora 2012 menunjukkan bahwa kandungan senyawa dari daun mangrove di perairan payau Kabupaten Cilacap banyak mengandung senyawa polar seperti fenolit, alkaloid, steroid, saponin, flavonoid dan tanin.

Tahap kedua dari penelitian ini adalah pembuatan sediaan nano emulsi dari ekstrak daun mangrove muda diperoleh hasil sebagai berikut:

1. Hasil optimasi pembuatan nano emulsi dengan teknik SNEDDS.

Pembuatan nano emulsi ektrak daun mangrove sebagai terapi anti kanker dilakukan dengan membuat formula berupa surfaktan (tween 80), ko-surfaktan dan minyak ikan. Setelah itu kami masukkan dalam software Design Expert versi 8.7.0.1. Diperoleh 14 formulasi yang berbeda, kemudian kami lakukan uji turbidatas dan uji transmitan untuk mengetahui dari ke-14 formulasi manakah formulasi yang memberikan sediaan nano emulsi dengan teknik SNEDDS yang terbaik. Adapun hasil uji turbiditas dan uji transmitan dari 14 formula menunjukan bahwa dari ke 14 formulasi yang mendapatkan nilai turbiditas 1 adalah formulasi no-1 (tabel 4).

Hasil turbiditas 1 menunjukan bahwa sediaan semakin jernih dan apabila formulasi memiliki nilai uji turbiditas 0 maka campuran akan semakin 


\begin{tabular}{cccccc} 
Tabel 4 | Hasil uji turbiditas dan uji transmitansi formula nano emulsi dengan teknik SNEDDS & \\
Formulasi & $\begin{array}{c}\text { Surfaktan } \\
\text { (Tween 80) }\end{array}$ & $\begin{array}{c}\text { Ko-surfaktan } \\
\text { (PEG 400) }\end{array}$ & $\begin{array}{c}\text { Minyak Ikan } \\
\text { Cucut }\end{array}$ & $\begin{array}{c}\text { Respons 1 } \\
\text { (Turbiditas) }\end{array}$ & $\begin{array}{c}\text { Respons 2 } \\
\text { (Transmitan) }\end{array}$ \\
\hline $\mathbf{1}$ & 2,667 & 2,667 & 2,667 & 0 & 0,9 \\
$\mathbf{2}$ & 3,500 & 3,500 & 1,000 & 0 & 1 \\
$\mathbf{3}$ & 6,000 & 1,000 & 1,000 & 1 & 96,2 \\
$\mathbf{4}$ & 4,333 & 1,833 & 1,833 & 0 & 0,8 \\
\hline $\mathbf{5}$ & 1,833 & 4,333 & 1,833 & 0 & 0,8 \\
\hline $\mathbf{6}$ & 1,000 & 3,500 & 3,500 & 0 & 0,8 \\
$\mathbf{7}$ & 6,000 & 1,000 & 1,000 & 1 & 95,3 \\
$\mathbf{8}$ & 1000 & 6,000 & 1,000 & 0 & 0,9 \\
$\mathbf{9}$ & 1000 & 1,000 & 6,000 & 0 & 0,8 \\
$\mathbf{1 0}$ & 1000 & 6,000 & 1,000 & 0 & 0,9 \\
$\mathbf{1 1}$ & 1000 & 1,000 & 6,000 & 0 & 0,8 \\
\hline $\mathbf{L}$ & 3,500 & 1,000 & 3,500 & 0 & 0,8 \\
$\mathbf{M}$ & 3,500 & 3,500 & 1,000 & 0 & 1,1 \\
\hline $\mathbf{N}$ & 1,833 & 1,833 & 4,333 & 0 & 0,8 \\
\hline
\end{tabular}

keruh. Analisis uji turbiditas dan uji transmitan dilakuan dengan spektrofotometer UV-Vis dengan panjang gelombang $650 \mathrm{~nm}$. Kemudian formula dengan uji turbiditas dan uji transmitan 1 dilakukan uji solusi atau uji perbandingan formula untuk memastikan formulasi sudah sesuai standar teknik SNEDDS. Hasil uji solusi menunjukan bahwa formulasi nano emulsi surfaktan, ko-surfaktan dan minyak ikan 6:1:1 memiliki nilai uji transmitan mendekati 100 dan menunjukan bahwa formulasi tersebut semakin jernih (tabel 5). Menurut penelitian, larutan yang memiliki nilai uji transmitan sebesar 100 adalah aquades yang memiliki bentuk jernih dan transparan.

2. Uji Optimasi Drug Loading.

Uji ini bertujuan untuk menentukan konsentrasi maksimal yang dicapai oleh ekstrak daun

Tabel 5 | Hasil uji solusi formulasi nano emulsi dengan teknik SNEDDS.

\begin{tabular}{cllllll} 
No & Tween 80 & PEG 400 & Minyak lkan & Turbiditas & Transmitan & Desibility \\
\hline 1 & 6,00 & 1,00 & 1,0 & 0,96 & 92,45 & 0,963 \\
2 & 1 & 3 & 3 & 0,05 & 5,905 & 0,054
\end{tabular}
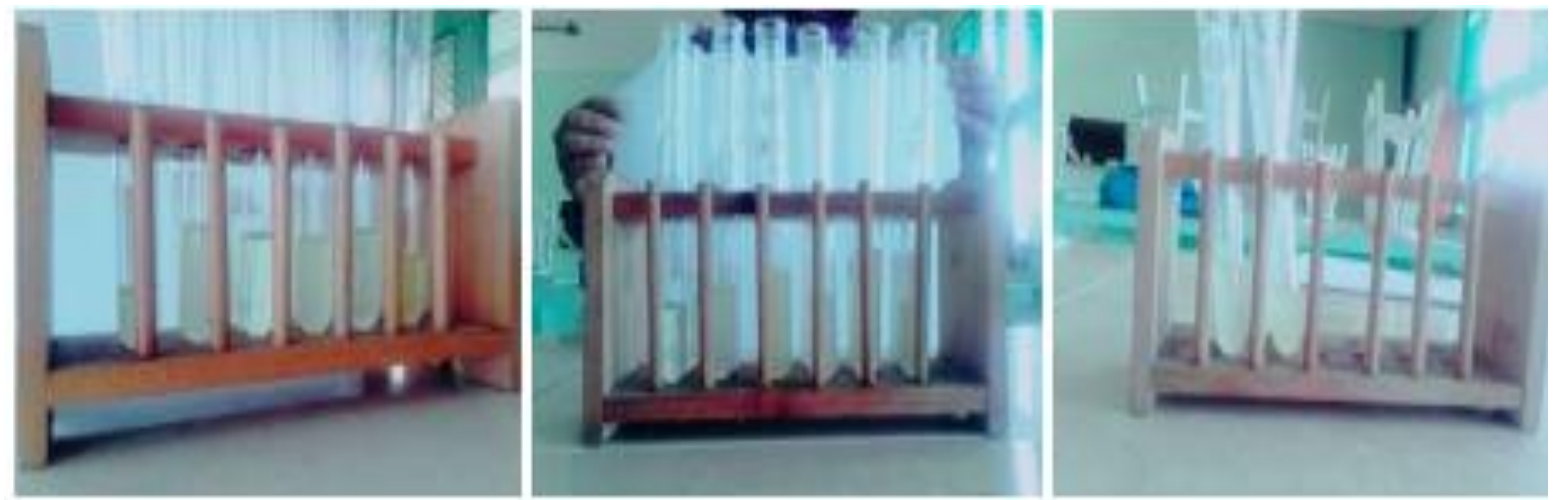

Gambar 1 | Formulasi nano emulsi dengan teknik SNEDDS 


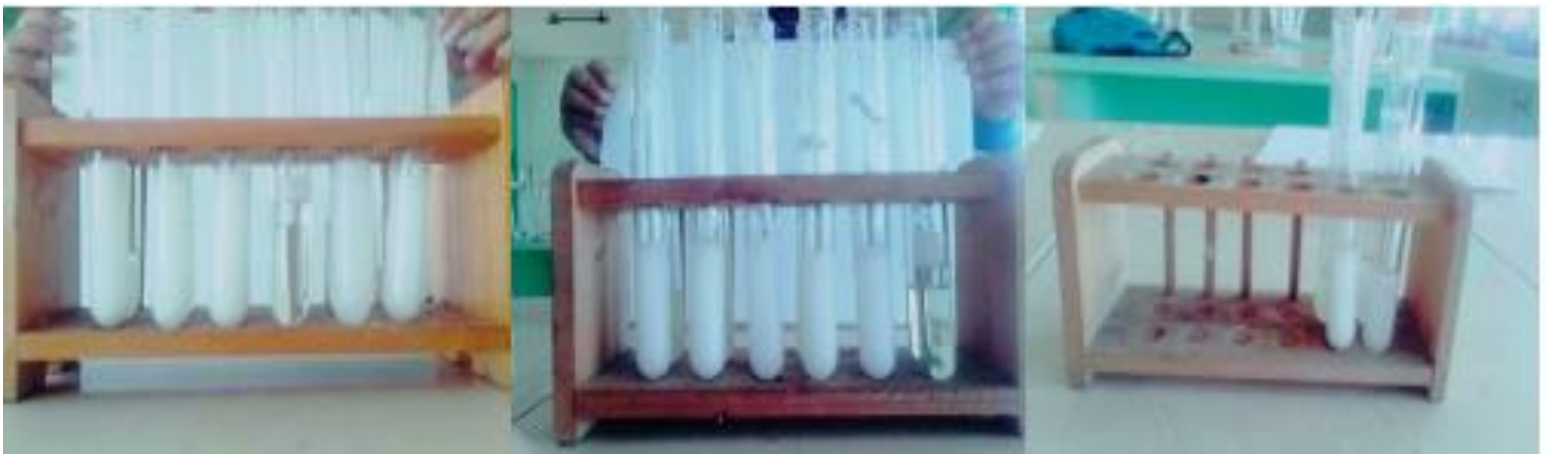

Gambar 2 | Hasil uji turbiditas formula nano emulsi teknik SNEDDS

mangrove Rhizophora mucronata dalam sistem (formula SNEDDS).

Langkah awal dalam uji ini adalah membuat formulasi dosis ektrak mangrove yang akan dimasukkan dalam formulasi nano emulsi. Dalam uji ini dibuat dosis keseragaman bobot yang terdiri dari $5 \mathrm{mg}, 10 \mathrm{mg}, 15 \mathrm{mg}, 20 \mathrm{mg}$, dan $25 \mathrm{mg}$. dari hasil uji optimasi drug loading diperoleh bahwa dosis ektrak daun mangrove yang tepat dalam membuat sediaan nano emulsi dengan teknik SNEDDS formula 6;1;1 sebesar $5 \mathrm{mg}$. pada dosis $5 \mathrm{mg}$ persediaan nano emulsi diperoleh hasil sediaan yang jernih setelah dilakukan uji drug loading kemudian campuran dilakukan uji Particle Size Analyzer (PSA). Uji PSA dilakukan untuk melihat ukuran partikel yang terdapat dalam sediaan nano emulsi (Wulandari, 2013).

Hasil uji PSA menunjukkan bahwa sediaan nano emulsi dengan perbandingan formula tween 80; PEG 400; minyak ikan; ekstrak daun mangrove sebesar 6;1;1;5 memiliki rerata diameter $18,1 \mathrm{~nm}$ (gambar 3) artinya ukuran partikel sediaan yang kami buat telah berbentuk nano emulsi atau nanopartikel.

\section{Calculation Results}

\begin{tabular}{|c|c|c|c|c|}
\hline Peak No. & S.p.rea Rotio & Mean & $S . D$ & Mode \\
\hline 1 & 0.95 & $16.5 \mathrm{~nm}$ & $8.2 \mathrm{~nm}$ & $12.4 \mathrm{~nm}$ \\
\hline 2 & 0.07 & $363.2 \mathrm{~nm}$ & $1179.3 \mathrm{~nm}$ & $262.4 \mathrm{~nm}$ \\
\hline 3 & - & $-\mathrm{nm}$ & $-\mathrm{nm}$ & $-\mathrm{nm}$ \\
\hline Total & 1.00 & $78.3 \mathrm{~nm}$ & $367.3 \mathrm{~nm}$ & $12.4 \mathrm{~nm}$ \\
\hline
\end{tabular}

\section{Cumulant Operations}
Z-Average
PI
$18.1 \mathrm{~nm}$
0.470

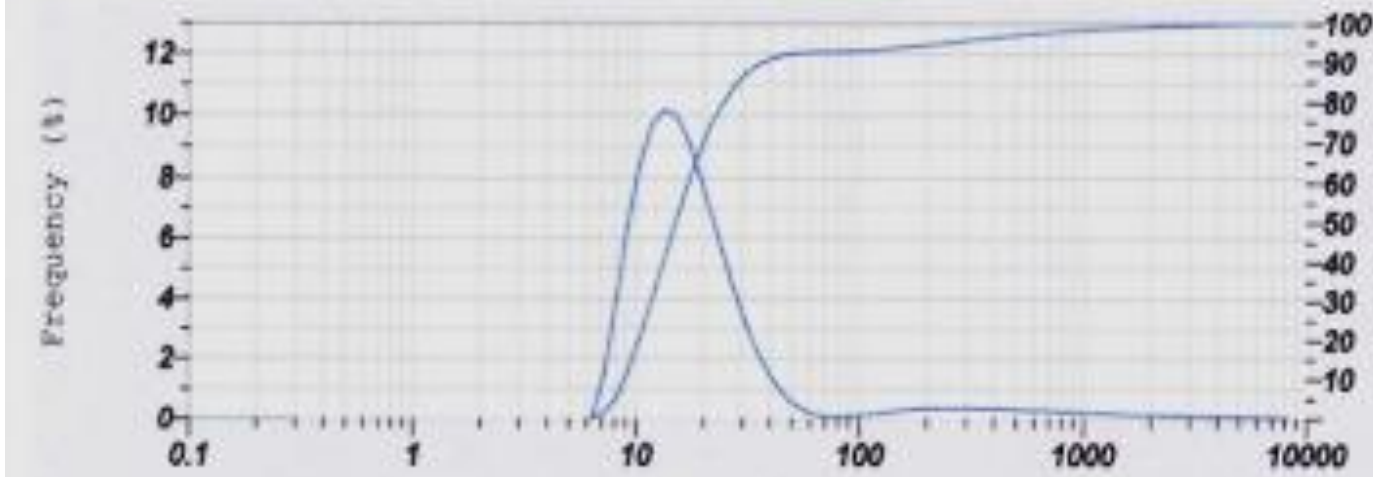

Gambar 3 | Hasil uji Particle Size Analyzer (PSA) 


\section{Uji Emulsification Time}

Uji ini bertujuan untuk mengetahui waktu campuran sediaan nano emulsi menjadi sediaan nano emulsi.

Waktu rata-rata sediaan nanopartikel (SNEDDS) teremulsi lebih cepat dari pada sediaan non SNEDDS (tabel 6).

\section{Uji Disolusi}

Uji disolusi bertujuan untuk mengetahui waktu disolusi sediaan. Hasil uji disolusi sediaan nano emulsi menunjukkan bahwa untuk sediaan SNEDDS formulasi dengan perbandingan tween 80; PEG 400; minyak ikan; ekstrak daun mangrove sebesar 6;1;1;5 (series1) memiliki waktu pelepasan zat aktif obat yang lebih baik dibanding sediaan bukan SNEDDS (series2) (Gambar 4). Hal ini dikarenakan pada menit-menit awal kadar zat aktif sediaan SNEDDS telah mencapai sekitar 40-60 ppm sedangkan pada sediaan bukan SNEDDS pada beberapa menit awal baru mencapai 10-30 ppm.

\section{Kesimpulan}

Dari hasil penelitian dapat diperoleh kesimpulan sebagai berikut:

1. Pembuatan ektrak daun mangrove yang memiliki rendemen tinggi adalah daun mangrove muda dengan pelarut etanol pa diperoleh hasil rendemen $200 \mathrm{gr}$ daun mangrove kering sebesar 18, $24 \%$

2. Ekstrak daun mangrove dapat dibuat sediaan nanoemulsi dengan teknik SNEDDS formulasi antara surfaktan; ko-surfaktan; minyak ikan; ekstrak daun mangrove sebesar $6 \mathrm{ml} ; 1 \mathrm{ml} ; 1 \mathrm{ml}$; $5 \mathrm{mg}$

3. Hasil uji partikel sedian nano emulsi formulasi antara surfaktan; ko-surfaktan; minyak ikan; ektrak daun mangrove sebesar $6 \mathrm{ml} ; 1 \mathrm{ml} ; 1 \mathrm{ml}$; $5 \mathrm{mg}$ sebesar 18,1 nm, uji Emulsification Time 1,503 menit dan uji disolusi sediaan lebih cepat daripada non sediaan SNEDDS

\section{Bibliografi}

1. Anggoro S, 2013. "Distribusi Logam Berat Timbal $(\mathrm{Pb})$ pada Tanaman Mangrove Rhizopora mucronata dan Avicennia marina di Perairan
Tabel 6 | Hasil uji emulsification time formula nano emulsi

\begin{tabular}{|l|c|c|} 
Replikasi & $\begin{array}{c}\text { SNEDDS } \\
\text { (menit) }\end{array}$ & $\begin{array}{c}\text { Non-SNEDDS } \\
\text { (menit) }\end{array}$ \\
\hline $\mathbf{1}$ & 1,58 & 5,53 \\
\hline $\mathbf{2}$ & 1,50 & 6,11 \\
\hline $\mathbf{3}$ & 1,43 & 6,09 \\
\hline Rata-rata & 1,503 & 5,61 \\
\hline
\end{tabular}

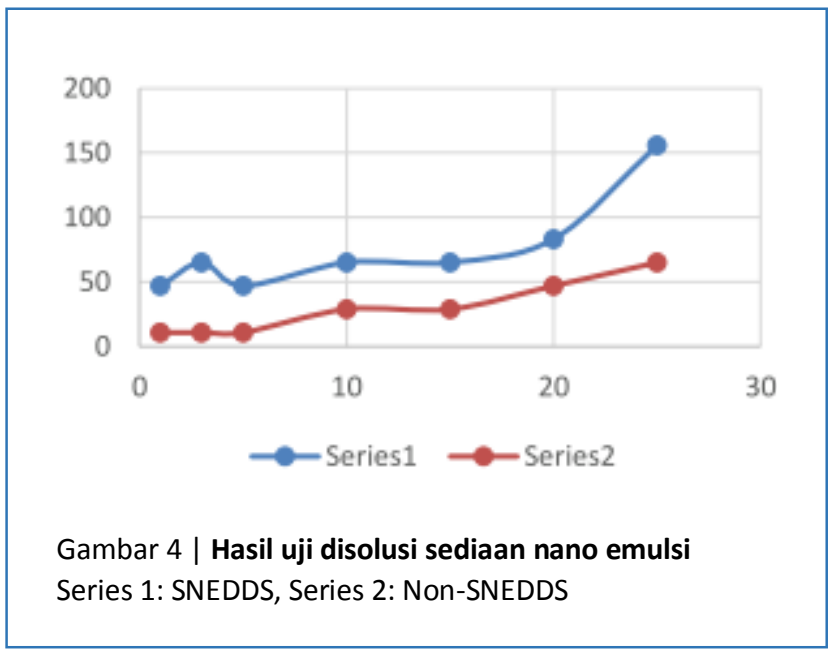

Segara Anakan" Seminar Nasional Prodi Teknik Kimia Universitas Muhammadiyah Purwokerto.

2. Feliatra. 1999. "Identifikasi Bakteri Patogen (Vibrio sp) di Perairan Nongsa Batam Provinsi Riau. Jurnal Natur Indonesia II.

3. Feliatra. 2000 "Studi Awal Tumbuhan Mangrove sebagai antimikroba" Lembaga Penelitian Universitas Riau.

4. Makadia, H.A., Batt,A.Y. 2013. "Self-Nano Emulsifying Drug Delivery Sistem (SNEDDS)" Future Aspects: Asian J. Pharm.(3):21-17

5. Purnobasuki H. 2004. "Potensi Mangrove sebagai Tanaman Obat" Universitas Airlangga Surabaya.

6. Yasmon, A. 2000. "Sensitifitas Vibrio Parahaemolyticus terhadap Ekstrak Mangrove Rhizopora Apiculata di Dalam Lumpur dan Air Laut. Skripsi Sarjana Fakultas Perikanan dan IImu Kesehatan Universitas Riau. 37p

7. Warsinah. 2009. "Antivitas Antikanker Ekstrak Etanol Daun Rhizopora mucronata Terhadap Larva Udang Artemia salina Leach dan Sel Raji" Jurnal Molekul.Vol.IV No.1.

8. Wulandari, 2013. "Formulasi SNEDDS untuk Gamavuton-0 dengan Mengunakan Minyak Nabati, Skipsi, S.Farm, Fakultas Farmasi Universitas Gadjah Mada Yogyakarta. 